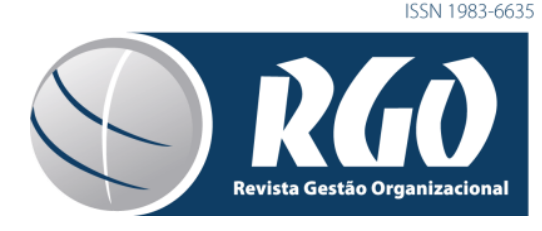

\title{
COMPLEMENTAÇÃO DA CABOTAGEM COM O MODAL RODOVIÁRIO PARA TRANSPORTE DE MAÇÃS DO SUL AO NORTE E NORDESTE DO BRASIL
}

\section{COMPLEMENTATION OF CABOTAGE WITH ROAD MODAL FOR APPLE TRANSPORT FROM SOUTH TO NORTH AND NORTHEAST OF BRAZIL}

\author{
KELI REGINA CADORE \\ Bacharel em Administração \\ Universidade do Oeste de Santa Catarina (Unoesc) \\ E-mail: keli_cadore@hotmail.com \\ Orcid: https://orcid.org/0000-0002-8742-6180 \\ PRISCIANA RECK \\ Bacharel em Administração \\ Universidade do Oeste de Santa Catarina (Unoesc) \\ E-mail: prisciana.reck@gmail.com \\ Orcid: https://orcid.org/0000-0002-4687-928X
}

\section{AUGUSTO FISCHER}

Professor do Mestrado Profissional em Administração

Universidade do Oeste de Santa Catarina (Unoesc)

E-mail: augusto.fischer@unoesc.edu.br

http://orcid.org/0000-0001-5310-2249

Endereço: Rua Nereu Ramos, 3777, Bairro Seminário, CEP 89.803-000 - Chapecó (SC).

\section{RESUMO}

Este trabalho analisa a viabilidade logística e econômica para a utilização da cabotagem em complementação ao transporte rodoviário de maçã, da Região Sul às Regiões Nordeste e Norte do Brasil. O objetivo do trabalho é analisar a viabilidade logística e econômica para a utilização da cabotagem em complemento ao transporte rodoviário de maçã da região Sul às regiões Nordeste e Norte do Brasil. O estudo caracteriza-se como pesquisa descritiva e pelas abordagens quantitativa e qualitativa. Para seu desenvolvimento foram utilizadas fontes primárias e secundárias de dados. Os dados primários foram coletados junto a uma empresa produtora e comercializadora de maçã, e junto a uma empresa operadora de cabotagem e uma transportadora. Os dados secundários foram extraídos de documentos relacionados às operações logísticas de modais rodoviários e de cabotagem. Os resultados apontam que a multimodalidade com a complementação da cabotagem ao transporte rodoviário mostra-se economicamente viável, mas quanto ao tempo demandado para o transporte até os mercados de destino, tornase inviável.

Palavras-chave: Transporte Rodoviário. Multimodalidade. Cabotagem. Maçã.

Data de submissão: 29/12/2017. Data de aceite: 25/03/2019. Data de publicação: 13/04/2019. 


\begin{abstract}
This paper analyzes the logistic and economic feasibility for the use of cabotage in complementation to the road transport of apple, from the South Region to the Northeast and North Regions of Brazil. The objective of this work is to analyze the logistic and economic feasibility for use of cabotage in complement to the road transportation of apple from South to the Northeast and North regions of Brazil. The study is characterized as descriptive research and quantitative and qualitative approaches. For its development primary and secondary data sources were used. The primary data were collected from an apple-producing and marketing company and from a cabotage operator and a carrier. The secondary data were extracted from documents related to the logistic operations of road and cabotage modals. The results show that multimodality with the complementation of cabotage to road transport is economically feasible, but as for the time demanded for transportation to the destination markets, it becomes infeasible.
\end{abstract}

Keywords: Road transport. Multimodality. Cabotage. Apple.

\title{
1 INTRODUÇÃO
}

A escolha dos modais de transporte adequado no sistema de logística, incluindo a utilização de intermodalidade ou multimodalidade, representa possibilidades de redução de custos e maior competitividade, incluindo além dos preços de fretes, tempo de entrega, preservação das condições dos produtos, e custos de seguro. Para o Brasil, consideradas as dimensões territoriais, a intermodalidade e a multimodalidade podem representar oportunidades de inovação em logística devido à possibilidade de se contornarem as dependências exclusivas ao modal rodoviário para o transporte de mercadorias.

Os custos logísticos no Brasil são mais caros quando comparados a outros países. Segundo o Instituto de Logística e Supply Chain - ILOS (2016a) estes custos representam mais de $11 \%$ do PIB nacional, com forte influência da atividade de transportes. Esses custos são justificados, principalmente, pela falta de infraestrutura que encarece os transportes devido aos altos dispêndios com insumos e manutenção de veículos.

O Brasil possui uma vasta costa marítima, com 7.367 quilômetros, conforme a CONFEDERAÇÃO NACIONAL DO TRANSPORTE (CNT, 2012). Essa extensão propicia a utilização de modais alternativos como a cabotagem. Para o transporte de mercadorias entre longas distâncias, como entre as regiões Norte-Nordeste e Sul do país, pode se complementar o modal da cabotagem ao modal rodoviário que, por sua vez, cobriria as curtas distâncias para a entrega, inclusive fracionada, de mercadorias aos destinatários finais.

A região Sul se destaca pela grande concentração de pomares de maçãs, em especial nos estados do Rio Grande do Sul e Santa Catarina. Conforme Kist et al. (2016), o setor tem grande relevância no desenvolvimento social e econômico da região, cuja cadeia proporciona $\mathrm{R} \$$ bilhões anuais em geração de riqueza ao país e 195 mil empregos diretos e indiretos. Como a maior parte da produção se concentra na região Sul, e o produto é distribuído aos principais mercados consumidores do território nacional, a escolha do modal adequado para a distribuição da maçã às regiões Norte e Nordeste pode proporcionar ganhos de qualidade do produto, satisfação de entrega, e redução de custos logísticos. Com base no exposto, levantou-se a 
seguinte a questão principal de pesquisa: a utilização do modal da cabotagem em complemento ao transporte rodoviário da maçã produzida no Sul para distribuição nas regiões Norte e Nordeste do país apresenta viabilidade logística e econômica?

Para responder à questão de pesquisa, o objetivo geral consiste em analisar a viabilidade logística e econômica para a utilização da cabotagem em complemento ao transporte rodoviário de maçã da região Sul às regiões Nordeste e Norte do Brasil. Especificamente visa avaliar a viabilidade logística da remessa de maçã por meio da cabotagem em complemento ao modal rodoviário, e comparar os custos entre a utilização do modal rodoviário de forma exclusiva, e a utilização dos modais complementares: rodoviário - cabotagem - rodoviário.

Entre as principais razões, este estudo teve como motivações, a identificação de produtos e clientes potenciais para o transporte pelo modal de cabotagem, a avaliação de possibilidades de utilização do transporte de maçã via cabotagem em complementação ao transporte rodoviário, configurando como alternativa a uma potencial redução de custos logísticos para a distribuição da maçã. Ainda sob a visão econômica, a utilização da cabotagem pode assegurar condições para a manutenção da qualidade e redução dos riscos de deterioração da fruta, e proporcionar satisfação aos clientes com a entrega da mesma. Estudos de utilização do modal de cabotagem também se justificam do ponto de vista socioambiental, pois sua utilização contribui como a redução da emissão de poluentes e a redução de acidentes rodoviários.

O trabalho caracteriza-se como uma pesquisa descritiva com abordagens quantitativas e qualitativas da pesquisa. Quanto aos procedimentos metodológicos caracteriza-se como pesquisa de campo e estudo documental, com dados de fontes primárias e secundárias. Para a realização do estudo, foram aplicadas entrevistas não estruturadas e semiestruturadas para coleta dos dados primários, e para os dados secundários foram utilizados como bases, os volumes de maçã comercializada por uma empresa nas regiões Norte e Nordeste do país, no período de 2013 a 2016.

O artigo está estruturado por cinco seções, incluindo esta seção da introdução. A segunda seção apresenta a revisão bibliográfica sobre a multimodalidade e intermodalidade, o transporte rodoviário, o transporte de cabotagem, e o setor da pomicultura. Na terceira seção são apresentados os procedimentos metodológicos para o desenvolvimento deste trabalho. A quarta seção apresenta os resultados deste estudo, e a quinta seção apresentará as considerações finais.

\section{REVISÃO BIBLIOGRÁFICA}

O sistema de transporte no Brasil é realizado por cinco tipos de modais, sendo eles: rodoviário, ferroviário, aquaviário, dutoviário e aéreo. Conforme dados da CNT (2016) o modal rodoviário é o mais representativo na logística de transportes do Brasil, respondendo por mais de $61 \%$ do transporte de cargas em geral.

A tabela 1 apresenta a participação dos modais da movimentação anual de cargas e passageiros no Brasil até julho de 2016. 
Tabela 1 - Participação dos modais da movimentação anual de cargas e passageiros (em \%)

\begin{tabular}{l|c|l|c}
\hline \multicolumn{1}{c|}{ Modal } & passageiros e cargas & \multicolumn{1}{|c|}{ Modal } & passageiros e cargas \\
\hline Rodoviário & 61,10 & Dutoviário & 4,20 \\
Ferroviário & 20,70 & Aéreo & 0,40 \\
Aquaviário & 13,60 & & \\
\hline
\end{tabular}

Fonte: CNT (2016).

O Brasil apresenta uma vasta extensão territorial, e grande produção de commodities, a qual contribui para a representatividade do modal rodoviário no país. O uso desse modal está relacionado à facilidade de acesso e confiabilidade, apesar de seus custos mais altos, e estar sujeito aos problemas de infraestrutura viária (CASTRO et al., 2016). Outra razão da concentração do transporte de cargas no modal rodoviário está relacionada à falta de estrutura em outros modais de transporte, como o ferroviário e o hidroviário, incluindo a cabotagem (BOENTE et al., 2016).

Esta grande representatividade gera pontos de discussão, principalmente pelos altos custos gerados às empresas. O Guia Marítimo (2016a) aponta que a integração física e operacional dos modais é fundamental para que seja otimizada a potencialidade de cada modal e trata também da multimodalidade como facilitadora de integração logística, permitindo redução de custos ambientais, sociais e financeiros na cadeia produtiva.

Para determinar a modalidade de transporte adequada na movimentação de uma determinada carga, alguns itens devem ser observados (SILVA; ARAÚJO; BRITO, 2018; RODRIGUES et al., 2014). A natureza e característica da mercadoria, tamanho do lote, disponibilidade e frequência, transbordos e rotas alternativas, restrições ao modal, confiabilidade de tempo de trânsito, valor do frete, risco de sinistralidade e nível de serviço agregado. Para Jacobsen (2011), alguns critérios devem ser seguidos na escolha do modal adequado. Uma análise da relação custobenefício deve ser feita, levando em consideração a carga que será transportada (volume, peso, quantidade, prazo de entrega, distância a percorrer) e as modalidades de transporte (condições de infraestrutura, valor do frete, custo, flexibilidade).

Jacobsen (2011) também ressalta algumas recomendações que podem contribuir para a escolha do modal adequado, considerando o valor dos produtos, e valor do frete. Quando a carga possui alta relação valor/peso, o recomendado é a utilização de meios de transporte mais rápidos, e quando a mercadoria possui baixa relação valor/peso, são recomendados veículos mais lentos. Os meios de transporte mais baratos precisam de grande quantidade de carga para o transporte e normalmente possuem tempo de percurso maior, fornecendo uma menor flexibilidade ao cliente. Uma vantagem competitiva na escolha do modal é o quesito velocidade, que combinado com o fator preço se torna imbatível (JACOBSEN, 2011).

Nas próximas subseções discute-se o transporte rodoviário e o modal da cabotagem e como os mesmos se complementam através da multimodalidade e intermodalidade. Também se apresenta a descrição do setor da pomicultura e as condições de armazenagem e transporte de maçã. 


\subsection{A INTERMODALIDADE E A MULTIMODALIDADE}

O transporte de cargas pode ocorrer dependendo de um ou mais veículos para o deslocamento da mercadoria a partir da sua origem até sua entrega no destino final. Para esses tipos de transporte utilizam-se as operações de multimodalidade ou intermodalidade.

Para atender às necessidades dos clientes, com a adequada combinação de agilidade e custos acessíveis, Silva, Araújo e Brito (2018) apontam que um único modal pode não ser suficiente. Segundo os autores, mesclar modais pode ser a melhor opção para obter as vantagens de redução de custos. Além disso, a deficiência ou insuficiência de estruturas em outros modais tornam o Brasil dependente do modal rodoviário (RIBEIRO; BOENTE, 2014). Os autores afirmam que o escoamento de cargas no Brasil é ineficiente devido à falta de estrutura em outros modais de transporte além do rodoviário.

A intermodalidade ou multimodalidade logística possibilita utilizar as vantagens técnicas e comerciais de cada modalidade. Também pode ser a solução para logísticas de transporte que buscam a redução de impactos sociais e ambientais adversos (SILVA; SPROESSER; SPERS, 2017; BOENTE et al., 2016; IANNONE, 2012).

Intermodalidade refere-se à movimentação de cargas, com a utilização de duas ou mais modalidades de transporte (SILVA; ARAÚJO; BRITO, 2018; SILVA; SPROESSER; SPERS, 2017; BOENTE et al., 2016; IANNONE, 2012). De acordo com a contratação do frete, Souza, Cremasco e Gabriel Filho (2016), e Ribeiro e Boente (2014) caracterizam a intermodalidade como sendo a operação em que a carga é transportada por mais de um modal, da origem ao destino, e com contratação de transporte interdependente com cada um deles. Isso significa que cada transportador irá emitir um documento de transporte para seu trajeto correspondente, e será responsável exclusivamente pela sua parcela do trajeto.

Apesar de suas vantagens, a intermodalidade ainda é pouco explorada no Brasil, devido às limitações da infraestrutura logística que integre diferentes modais, bem como à escassez de investimentos para este fim (BOENTE et al., 2016; SILVA; ARAÚJO; BRITO, 2018). Medeiros (2014) ressalta que a multimodalidade dos meios de transporte com uso intensivo dos meios modernos de comunicação pode resultar da eliminação de restrições regulatórias à fusão de empresas de modais diferentes, da livre concorrência, e da redefinição de serviços que melhor atendam aos interesses de usuários de cargas.

A contratação intermodal é comum quando não há disponibilidade de transporte por modal único para o destino desejado, ou quando este tipo de transporte se apresenta mais vantajoso do que a contratação de um único modal de transporte (BOENTE et al., 2016; KEEDI, 2003). Essa operação pode ser realizada com o auxílio de empresas prestadoras de serviços ou pelo próprio embarcador, mas sempre em nome do dono da carga, ou seja, o embarcador. A emissão de conhecimento de transporte deve ser feita pelo transportador contratado (KEEDI, 2003).

Assim como a intermodalidade, a multimodalidade se caracteriza pela combinação de vários modais entre a origem e o destino, dependendo das rotas e principalmente, dos produtos a serem movimentados. A operação de multimodalidade ocorre quando a contratação de fretamentos de cargas utiliza-se de mais de um modal de transporte, mas, diversamente da operação de intermodalidade, é realizada por um Operador de Transporte Multimodal - OTM, 
que se responsabiliza pelo transporte total da mercadoria, da origem ao destino final (SOUZA; CREMASCO; GABRIEL FILHO, 2016; KEEDI, 2003).

No Brasil, o transporte multimodal de cargas é regido pela Lei № 9.611/98, que, além disso, criou a entidade do OTM (BRASIL, 1998). O OTM é pessoa jurídica responsável pela realização do transporte de cargas, da origem até o destino final, por meios próprios, ou por subcontratação de transportadores (BOENTE et al., 2016; SOUZA; CREMASCO; GABRIEL FILHO, 2016). Isso significa que o OTM responde exclusivamente a seu embarcador e, por sua vez, em caso de danos e avarias, é quem poderá recorrer a seus transportadores subcontratados.

No entanto, Lima e Pasin (1999 apud RIBEIRO; BOENTE, 2014) apontam que a desvantagem na utilização do transporte multimodal, reside na oferta de novas rotas de transporte. Ainda complementam que as desvantagens não se referem somente à falta de estrutura de transportes, mas também ao complexo arcabouço jurídico e burocrático, influenciando o funcionamento eficiente do OTM, cuja condição é importante para a redução dos custos de transporte.

\subsection{O TRANSPORTE RODOVIÁRIO}

O transporte rodoviário teve sua expansão em vários países após a segunda guerra mundial. Devido aos processos de interiorização em diversos continentes, o transporte rodoviário transformou-se num importante elo entre as áreas mais remotas dos grandes centros produtores (SILVA, 2004).

Segundo Keedi (2003), o modal rodoviário apresenta uma característica única que o diferencia dos demais modais, que é a capacidade de tráfego por qualquer via. O modal não se prende a trajetos fixos, tendo a flexibilidade de transitar por qualquer lugar. Outro diferencial do modal, ainda de acordo com Keedi (2003), é que ele é o único a praticar a multimodalidade em toda a sua plenitude, auxiliando assim os demais transportes.

Por estas características, este apresenta elevada confiabilidade, pois mesmo com custos mais altos, por meio de sua flexibilidade, não sofre alternâncias nos processos de entrega de cargas, e evita processos de transbordo, ao contrário do modal ferroviário e do modal hidroviário, que estão sujeitos a interferências, comprometendo a confiabilidade de entrega (SILVA; ARAÚJO; BRITO, 2018; CASTRO et al., 2016). Reis et al. (2013), ressaltam que o sistema rodoviário apresenta confiabilidade elevada, pois o modal de transporte rodoviário possui efetividade devido à possibilidade de chegar a seus destinos, sem sofrer interrupções de entrega.

A natureza do transporte rodoviário permite que o mesmo possa ter uma grande acessibilidade, fazendo com que as cargas sejam transportadas a territórios afastados. Essa capilaridade faz com que esse modal tenha uma alta versatilidade sendo uma importante conexão nas operações multimodais e intermodais (SILVA, 2004).

Rodrigues (2007) destaca que o modal rodoviário é um dos mais simples e eficientes dentre pontos a pontos. Sua única exigência são rodovias pavimentadas e de boa qualidade para auxiliar nos resultados, visto que o modal apresenta um elevado consumo de combustível (óleo diesel por tonelada de carga transportada por quilometro).

Mas Reis et al. (2013) alertam para a necessidade de se avaliar algumas variáveis com cautela, pois as vantagens de velocidade de entrega e custos de fretes podem se reverter com 
aumentos de preços de combustíveis. lannone (2012) aponta para as externalidades negativas proporcionadas pela logística de transporte, tais como, poluição o ar, geração de ruídos, congestionamentos de vias urbanas, acidentes de trânsito, e outros danos ambientais, sendo o modal rodoviário responsável pela maior parte desses custos de externalidades. Apesar de ser o modal de transporte mais utilizado, o modal rodoviário é responsável pela maior parte dos custos externos de transporte de cargas (IANNONE, 2012).

Keedi (2003) afirma que o modal possui pequena capacidade de carga, que aliado ao alto custo de sua estrutura o torna relativamente caro, quando comparado aos demais modais. Outra desvantagem do modal, de acordo com Fachinello e Nascimento (2008) é a falta de investimento na infraestrutura do país, considerando que ouve uma deterioração na malha rodoviária sem que houvesse uma maior demanda dos demais modais de forma a substituí-lo. Além disso, no Brasil, a distribuição física ainda é feita preferencialmente durante o dia, congestionando as principais artérias das cidades, aumentando os índices de poluição, produzindo um desempenho medíocre e acelerando o desgaste das frotas (RODRIGUES, 2007).

A malha rodoviária nacional possui uma extensão total de 1.720.914,1 km (Quadro 1). A malha rodoviária nacional pavimentada é composta por $211.902,6 \mathrm{~km}$, sendo assim dividida por federal, estadual e municipal, e tendo maior representatividade a malha pavimentada estadual, conforme ressaltado no quadro 1, com $119.747,0 \mathrm{~km}$ de extensão.

Quadro 1 - Malha rodoviária e frota de veículos no Brasil

\begin{tabular}{|c|c|c|c|c|c|}
\hline \multicolumn{4}{|c|}{ Malha rodoviária - extensão em km } & \multicolumn{2}{|l|}{ Frota de veículos (unidade) } \\
\hline Rodovia & Pavimentada & \begin{tabular}{|c|} 
Não \\
Pavimentada
\end{tabular} & Total & Caminhão & 2.665 .192 \\
\hline Federal & $65.328,9$ & $11.183,3$ & $76.512,2$ & Cavalo mecânico & 600.491 \\
\hline Estadual & $119.747,0$ & $105.600,6$ & $225.347,6$ & Reboque & 1.345 .819 \\
\hline Municipal & $26.826,7$ & $1.234 .918,3$ & $1.261 .745,0$ & Semirreboque & 885.596 \\
\hline Rede Planejada & & & $157.309,3$ & Ônibus interestaduais e internacionais & 19.923 \\
\hline Total & $211.902,6$ & $1.351 .702,2$ & $1.720 .914,1$ & Intermunicipais & 57.000 \\
\hline \multicolumn{4}{|c|}{ Malha rodoviária sob concessão - extensão em km } & $\begin{array}{l}\text { Fretamento } \\
\text { Urbanos }\end{array}$ & $\begin{array}{r}25.205 \\
107.000\end{array}$ \\
\hline \multicolumn{3}{|c|}{$\begin{array}{l}\text { Administrada por concessionárias privadas } \\
\text { Administradas por operadoras estaduais }\end{array}$} & $\begin{array}{r}19.463 \\
1.195\end{array}$ & № de terminais rodoviários & 173 \\
\hline
\end{tabular}

Fonte: CNT (2016).

Considerando a malha rodoviária não pavimentada, de acordo com o quadro 1 sua extensão é de $1.351 .702,2 \mathrm{~km}$, representando 6 (seis) vezes a malha rodoviária pavimentada. A extensão da malha rodoviária municipal não pavimentada é de $1.234 .918,3 \mathrm{~km}$, correspondendo a maior parcela da malha não pavimentada.

O transporte rodoviário, conforme ressaltado por Novaes (2015), possui uma grande vantagem logística, pois possui a capacidade de alcançar praticamente qualquer ponto do território nacional, com exceção de locais muito remotos, que não possuem expressão econômica para utilizar este meio de transporte. Rodrigues et al. (2014) relacionam outras vantagens, como a cobertura geográfica, disponibilidade de vias de acesso, possibilidade do serviço porta a porta, embarques e partidas mais rápidas e de pequenos lotes, rapidez de entrega, e maior possibilidade de substituição de veículo em caso de dano. Entre as desvantagens citadas pelo autor destacam- 
se o maior custo operacional e menor capacidade de carga, o congestionamento nas rodovias em épocas de safra e o desgaste da malha rodoviária.

\subsection{TRANSPORTE DE CABOTAGEM}

Devido às desvantagens econômicas apresentadas no modal rodoviário para longas distancias e grande estoque de mercadorias, engloba-se como alternativa de economia a cabotagem (SILVEIRA; FELIPE JUNIOR, 2013; KEDI; MENDONÇA, 2000). Keedi e Mendonça (2000) definem a cabotagem como o transporte de cargas entre os portos marítimos nacionais, ou entre portos marítimos nacionais e portos interiores do país localizados em rios.

Em definição da empresa especializada em cabotagem no Brasil, a Logística Intermodal S/A (LOG-IN, 2016a), a cabotagem é a navegação entre portos de um mesmo país, se contrapondo à navegação de longo curso, a qual é realizada entre portos de diferentes países. O modal de cabotagem é considerado promissor, considerando que o Brasil possui uma extensa costa navegável. O Quadro 2 apresenta o mapa de linhas de cabotagem com seus respectivos portos do Brasil.

Quadro 2 - Porto de navegação para linhas de cabotagem

\begin{tabular}{|l|l|l|l|l|l|l|l|}
\hline UF & Portos & UF & Portos & UF & Portos & UF & Portos \\
\hline AL & Maceió & AM & Manaus & AP & Santana & BA & Salvador, Aratu \\
\hline CE & Fortaleza & ES & Vitória & MA & Itaqui & PA & $\begin{array}{l}\text { Belém, Santarém, Vila do } \\
\text { Conde }\end{array}$ \\
\hline PB & Cabedelo & PE & Recife, Suape & PR & $\begin{array}{l}\text { Antonina, } \\
\text { Paranaguá }\end{array}$ & RJ & $\begin{array}{l}\text { Forno, Rio de Janeiro, } \\
\text { Itaguaí, Angra dos Reis }\end{array}$ \\
\hline RN & $\begin{array}{l}\text { Areia Branca, } \\
\text { Natal }\end{array}$ & RS & $\begin{array}{l}\text { Porto Alegre, } \\
\text { Rio Grande }\end{array}$ & SC & $\begin{array}{l}\text { Imbituba, Itajaí, São } \\
\text { Francisco do Sul }\end{array}$ & SP & São Sebastião, Santos \\
\hline
\end{tabular}

Fonte: Ministério dos Transportes (apud CNT, 2013).

A utilização de contêineres possui grande reflexo no transporte de cargas nos portos brasileiros, tornando assim a utilização da cabotagem uma opção viável. Sua utilização expressiva na movimentação de produtos nos portos nacionais, para importação e exportação mostram que as movimentações de cargas por meio da cabotagem é uma alternativa viável (CRUZ; ALENCAR; ARAUJO, 2015).

Alguns benefícios da cabotagem são baixo índice de avarias e roubo de cargas, valores de seguro menores, menor taxa de emissão de $\mathrm{CO}^{2}$ na atmosfera, eficiência energética, e de acordo com a Log-In (2016b), melhor relação de custo para distâncias acima de $1.500 \mathrm{~km}$. Um estudo da Ilos (2016b) aponta que para cada contêiner já em utilização da cabotagem, ainda existam outros 6,5 com potencial de deixar o modal rodoviário e agregar-se á cabotagem. O impacto seria benéfico, não apenas as empresas em sua redução de custos estimadas entre $25 \%$ e $30 \%$, mas também a fatores ambientais.

Conforme a Agência Nacional de Transportes Aquaviários (ANTAQ, 2016), em 2015 o modal de cabotagem, sobre todos os perfis de carga, apresentou aumento de 0,03\% em comparação a 2014. Considerando apenas a cabotagem em utilização de contêineres, o aumento 
foi de 2,3\%, comparando 2014. A tabela 2 demonstra a representatividade do modal e da utilização de cada carga, sendo o contêiner o 3 o colocado na classificação.

Tabela 2 - Movimentação de cargas na utilização de cabotagem no Brasil

\begin{tabular}{|c|c|}
\hline Modo de Cargas & (\%) \\
\hline Granel Líquido e Gasoso & 71,2 \\
\hline Granel Sólido & 13,2 \\
\hline Contêiner & 10,0 \\
\hline Geral Solta & 5,7 \\
\hline
\end{tabular}

Fonte: ANTAQ (2016)

O modal acaba por exigir das empresas maior planejamento para distribuição de seus produtos, visto que o navio passa pelo porto uma vez por semana, em alguns casos duas vezes por semana. Porém esse fator acaba sendo compensado, pelo custo mais baixo, maior segurança, integridade e confiabilidade proporcionados pelo modal maritimo (GUIA MARITMO, 2016b).

Os beneficios da cabotagem não se restringem apenas à grande extenção costeira do Brasil. Entre outros pontos positivos estão: grande capacidade de carregamento, maior vida útil dos equipamentos e veiculos, menor consumo de combustivel por tonelada transportado, reduzindo o registro de acidentes, menor custo por tonelada-quilometro, menor custo de seguro, além da menor emissão de poluentes (CNT, 2013).

A CNT (2013), aponta que apesar do seu elevado potencial de utilização, esse tipo de navegação sofre com diversos fatores que restrigem o seu crescimento. Destacam-se as altas tarifas incidentes no setor (como carregamento, descarregamento e armazenagem de mecadorias), grande nível de burocracia nas operações nos portos, alta carga tributária, carencia em infraestrutura portuária (baixa profundidade dos canais, má qualidade dos acessos aos terminais portúarios) idade elevada da frota e número limitado de embarcações.

Apesar de sua importância econômica e na articulação de cargas entre portos no país, a logística de transporte marítimos de cabotagem é incipiente quando comparada ao transporte pelo modal rodoviário (SILVEIRA; FELIPE JUNIOR, 2013). Conforme os autores, a extensa costa litorânea brasileira, que tem mais de oito mil quilômetros, apresenta condições propícias à cabotagem. Ainda de acordo com Silveira e Felipe Junior (2013), o transporte de cabotagem era forte no Brasil, entre as décadas de 1950 a 1970, período em que se manteve por meio da reserva de mercado e de empresas estatais que operavam no setor, criando-se demanda na indústria naval nacional. Contudo, a desregulamentação do setor e a política neoliberal desmantelaram a cabotagem.

Conforme Fachinello e Nascimento (2008), embora o setor demonstre uma tendência de crescimento, o modal ainda encontra algumas barreiras que se demonstram de difícil resolução. Dentre as barreiras encontradas pode se destacrar: baixa produtividade dos portos quando comparado a outros países, elevados custos de encarodos sociais, inexistencia do serviço de carga fracionada, grande burrocracia públicia e a falta de navios e contêineres específicos para cabotagem. 


\subsection{A POMICULTURA}

A pomicultura, ou atividade de produção de maçã, no contexto nacional possui destaque mundial, sendo a décima segunda em volume de produção, com 1.231,47 toneladas de maçã produzidas na safra de 2014/2015 (EPAGRI/CEPA, 2015). Com base no Sistema IBGE de Recuperação Automática/ Instituto Brasileiro de Geografia e Estatística (IBGE/ SIDRA, 2016), a Região Sul é responsável por mais de $99 \%$ da produção nacional de maçã (tabela 3), a qual, segundo Kist (2016), conta com 4.321 produtores, assim distribuídos: 2.763 em Santa Catarina, 1.170 no Rio Grande do Sul e 388 no Paraná.

Tabela 3 - Produção de maçã, de 2011 a 2015 (ton)

\begin{tabular}{lrrrrr}
\hline \multicolumn{1}{c}{ UF } & \multicolumn{1}{c}{$\mathbf{2 0 1 1}$} & \multicolumn{1}{c}{$\mathbf{2 0 1 2}$} & $\mathbf{2 0 1 3}$ & $\mathbf{2 0 1 4}$ & $\mathbf{2 0 1 5}$ \\
\hline Bahia & 480 & 1.245 & 702 & 870 & 870 \\
Minas Gerais & 3.713 & 3.289 & 4.128 & 4.082 & 5.046 \\
São Paulo & 1.153 & 3.665 & 3.742 & 2.961 & 5.446 \\
Paraná & 58.537 & 50.975 & 49.188 & 47.203 & 40.949 \\
Santa Catarina & 640.676 & 659.756 & 530.725 & 633.079 & 613.828 \\
Rio Grande do Sul & 634.436 & 620.841 & 642.987 & 690.422 & 598.512 \\
\hline TOTAL & $\mathbf{1 . 3 3 8 . 9 9 5}$ & $\mathbf{1 . 3 3 9 . 7 7 1}$ & $\mathbf{1 . 2 3 1 . 4 7 2}$ & $\mathbf{1 . 3 7 8 . 6 1 7}$ & $\mathbf{1 . 2 6 4 . 6 5 1}$ \\
\hline
\end{tabular}

Fonte: IBGE/SIDRA - Produção Agrícola Municipal (2016)

A comercialização da maçã representa, no mercado interno, um faturamento de $R$ \$ 2,1 bilhões (KIST et al., 2016). Dados da previsão de safra brasileira (SIDRA/IBGE, 2016), apontam que a produção de maçã no ano de 2015 foi de 1.262 .583 toneladas e de 1.041 .293 toneladas em 2016.

No estado de Santa Catarina os principais pomares estão localizados em cidades de altitude mais elevadas, que são favoráveis à cultura da maçã. Na serra catarinense, a cidade de São Joaquim se destaca na produção de maçã juntamente com Fraiburgo, localizado no Planalto do Meio Oeste. As principais áreas produtoras do Rio Grande do Sul são Vacaria, nos Campos de Cima da Serra, e Caxias do Sul, na Serra. A Região Sul do Paraná possui Lapa e Palmas como principais cidades produtoras. (KIST et al., 2016). Os municípios de São Joaquim (SC) e Vacaria (RS) disputam a liderança na produção nacional de maçã, seguidos por Fraiburgo. Os dois primeiros, devido à sua participação na produção nacional, são intitulados como Capital Nacional da Maçã. Fraiburgo (SC) é chamada de Terra da Maçã (KIST et al., 2016).

O transporte da maçã deve ser realizado da forma em condições que assegurem a manutenção da qualidade da fruta. A Empresa Brasileira de Pesquisa Agropecuária - Embrapa (apud SOCIEDADE NACIONAL DE AGRICULTURA - SNA, 2014) recomenda que o transporte e a armazenagem de frutas e hortaliças, dentre elas a maçã, deve ser realizado com o seu resfriamento. Para um armazenamento refrigerado adequado o fator mais importante é a temperatura, aliada à umidade relativa e à circulação do ar.

A temperatura de armazenagem é responsável por $70 \%$ de uma boa conservação. A maçã deve ser armazenada a uma baixa temperatura, entre 0 으 e $1 ㅇ$, uma variação de 1 으 $\mathrm{C}$ a 2 으 $\mathrm{C}$ acima ou abaixo da temperatura recomendada pode ser prejudicial à qualidade da fruta. Devido a isso é fundamental que não ocorra a interrupção da flutuação do ar na câmara fria garantindo uma 
temperatura uniforme. Para auxiliar na diminuição das flutuações de temperatura o empilhamento das frutas deve ser adequado, para assim não bloquear a passagem de ar entre elas. A umidade relativa do ar deve ser adequada, pois quando muito baixa produz a desidratação da fruta, tornando a mesma murcha, e quando muito alta, pode provocar o apodrecimento do vegetal. (EMBRAPA apud SNA, 2014).

O transporte adequado da maçã, utilizando via marítima, deve ocorrer em um container refrigerado, o qual, de acordo com Mendonça (sd), é equipado com um sistema de refrigeração, que funciona utilizando uma conexão elétrica, ideal para o transporte de produtos perecíveis. A utilização desse container possui como objetivo a manutenção da qualidade do produto, fazendo com que o mesmo não se deteriore.

Conforme Relatório do MAPA (2013), a Região Sul do país possui 219 packing houses, com uma capacidade de armazenagem de 709.821 toneladas (Tabela 4).

Tabela 4 - Número de packing houses e capacidade de armazenagem a frio

\begin{tabular}{lrr}
\hline \multicolumn{1}{c}{ Estado } & No de Packing Houses & Capacidade de Armazenagem(t) \\
\hline Santa Catarina & 90 & 409.000 \\
Rio Grande do Sul & 110 & 373.649 \\
Paraná & 19 & 11.172 \\
\hline Total & $\mathbf{2 1 9}$ & $\mathbf{7 0 9 . 8 2 1}$ \\
\hline
\end{tabular}

Fonte: MAPA (2013).

O armazenamento de maçãs em câmaras frias é de máxima importância para garantir o abastecimento ao longo de todo o ano. As variedades armazenadas são gala e Fuji em sua maioria, representando $55 \%$ das maçãs da variedade gala, com pico de colheita em fevereiro, e $40 \%$ da variedade fuji, com seu auge de colheita em abril. As tecnologias disponíveis de pós-colheita permitem que a maçã da variedade gala sejam armazenadas até o mês de dezembro, e as maçãs da variedade fuji, até o mês de fevereiro do ano seguinte. A capacidade total de armazenagem no Brasil representa 65\% da safra total de maçãs (MAPA, 2013).

\section{PROCEDIMENTOS METOdOLÓGICOS}

O presente trabalho utiliza a abordagem da pesquisa qualitativa com recorrência à abordagem quantitativa. Por meio da abordagem qualitativa busca se descrever a complexidade do problema e analisar a interação de certas variáveis (FACHIN) 2006). Também utilizou a abordagem quantitativa para o tratamento dos dados de variáveis referente a custos e volumes, para os quais se requer o uso de técnicas matemáticas. Quanto aos objetivos de pesquisa, a mesma caracteriza-se como pesquisa descritiva (GIL, 2010), cuja finalidade é descrever as características do objeto de pesquisa e identificar possíveis relações entre as variáveis do mesmo.

Para o desenvolvimento do estudo utilizou-se os procedimentos da pesquisa de campo para os dados primários. A coleta de dados primários foi realizada por meio de entrevistas não estruturadas e semiestruturadas, sendo os dados referentes à comercialização, inicialmente solicitou-se a ABPM, a qual se considerou que os dados de vendas do setor para as regiões Norte e Nordeste do Brasil, não eram disponíveis. Solicitou-se a duas empresas do setor de pomicultura, sediadas no estado de Santa Catarina, obtendo-se retorno apenas de uma empresa (Produtora). Os dados sobre transporte rodoviário foram solicitados junto a 15 empresas que prestam serviços 
de transporte no território nacional, mas destas, obteve-se retorno somente de uma Transportadora. Os dados relacionados ao transporte multimodal e intermodal da cabotagem foram solicitados a 3 empresas, obtendo-se retorno apenas de uma Operadora, a qual pratica a multimodalidade de cabotagem complementada ao transporte rodoviário.

Quanto aos dados secundários, este estudo caracteriza-se como pesquisa documental (FACHIN, 2006; MARCONI; LAKATOS, 2010), a qual compreende a consulta a documentos relacionados aos modais de transporte rodoviário e de cabotagem, e ao setor da pomicultura. Os dados do setor de transporte foram coletados no sítio eletrônico da CNT, referente ao período de 2013 a 2016, e na ANTAQ, referentes ao ano de 2016. Também foram coletados dados secundários junto a portais eletrônicos e empresas especializadas em logística. Os dados referentes ao setor da pomicultura foram coletados junto às bases de dados da ABPM, do IBGE, e da Epagri/Cepa. Para o tratamento dos dados foram utilizadas as técnicas de análise e descrição de conteúdo, dos resultados apurados de documentos, informações coletadas com as entrevistas e dados primários.

\section{APRESENTAÇÃO E DISCUSSÃO DOS RESULTADOS}

Nesta seção serão apresentados e discutidos os resultados deste estudo, referente à alternativa de transporte da maçã comercializada pela empresa objeto, sediada em Santa Catarina, aos estados do Norte e Nordeste do Brasil. Os resultados comparam as condições logísticas para o transporte rodoviário exclusivo, atualmente adotado, e o transporte multimodal rodoviário - cabotagem - rodoviário a propor. Também se comparam os dispêndios para o transporte rodoviário, e o transporte multimodal proposto.

\subsection{A LOGÍSTICA}

Para as avaliações os processos logísticos do transporte rodoviário e da cabotagem, desde a origem até o destino final, como também a documentação utilizada em cada modal, comparando as condições de cada modal, objeto deste trabalho, tomaram-se por base os volumes de maçãs comercializados pela Produtora de maçã, aos estados do Norte e Nordeste do Brasil, cujo transporte é realizado exclusivamente pelo modal rodoviário (Tabela 5).

Tabela 5 - Volume de vendas de maçãs da Produtora para o Norte e Nordeste do país, de 2013 a 2016 (t)

\begin{tabular}{lrrrrr}
\hline Estado & $\mathbf{2 0 1 3}$ & $\mathbf{2 0 1 4}$ & $\mathbf{2 0 1 5}$ & $\mathbf{2 0 1 6}$ & Total \\
\hline Amapá & 205 & 188 & 281 & 188 & 862 \\
Amazonas & 658 & 723 & 905 & 601 & 2.887 \\
Bahia & 200 & 3.144 & 1.592 & 1.879 & 6.815 \\
Ceara & 786 & 1.367 & 998 & 653 & 3.804 \\
Pará & 2.205 & 3.205 & 3.585 & 1.923 & 10.918 \\
Paraíba & 38 & 660 & 1.121 & 533 & 2.352 \\
Pernambuco & 1.449 & 1.878 & 980 & 916 & 5.223 \\
Piauí & 908 & 1.653 & 679 & 475 & 3.715 \\
Rio Grande do Norte & 948 & 784 & 1.585 & 177 & 3.494 \\
Sergipe & 774 & 681 & 728 & 482 & 2.665 \\
\hline
\end{tabular}

Fonte: Produtora 
Busca-se apurar, de forma geral, os resultados relacionados às condições de logística para o transporte da maçã até os mercados da fruta. Os volumes mais representativos na região Norte são os do estado do Pará com 10.918 toneladas, e na região Nordeste o estado da Bahia com 6.815 toneladas. Os volumes apresentados na tabela 6 correspondem a um total de 2.016 containers de 40 pés, com capacidade para 21,2 toneladas de maçã por container.

Tabela 6 - Quantidade de containers para o transporte da maçã

\begin{tabular}{lrrrrr}
\hline Estado & $\mathbf{2 0 1 3}$ & $\mathbf{2 0 1 4}$ & $\mathbf{2 0 1 5}$ & $\mathbf{2 0 1 6}$ & Total \\
\hline Amapá & 10 & 9 & 13 & 9 & 41 \\
Amazonas & 31 & 34 & 43 & 28 & 136 \\
Bahia & 9 & 148 & 75 & 89 & 321 \\
Ceará & 37 & 65 & 47 & 31 & 180 \\
Pará & 104 & 151 & 169 & 91 & 515 \\
Paraíba & 2 & 31 & 53 & 25 & 111 \\
Pernambuco & 68 & 89 & 46 & 43 & 246 \\
Piauí & 43 & 78 & 32 & 22 & 175 \\
Rio Grande do Norte & 45 & 37 & 75 & 8 & 165 \\
Sergipe & 37 & 32 & 34 & 23 & 126 \\
\hline
\end{tabular}

Fonte: Os Autores

Para o acondicionamento das cargas para longas distâncias normalmente é utilizada carga refrigerada, através de carretas frigoríficas, mas eventualmente algum cliente transporta em carga seca, o que segundo a Produtora é indesejável e não recomendado.

Os processos logísticos do transporte multimodal, que envolvem o transporte pelo modal rodoviário, complementado com a cabotagem, e concluído com o modal rodoviário até o destino final, iniciam com a reserva ou booking da carga, e agendamento da coleta e entrega da carga. Após o envio do booking, a Operadora parte para a coleta no local de origem por transporte rodoviário até a destinação ao terminal portuário de origem. Em seguida, processa o embarque e o transporte de cabotagem até o porto de destino, onde processa a coleta para o transporte rodoviário para entrega ao destino final (LOG-IN, 2017). A figura 1 apresenta o fluxo do transporte multimodal, utilizado em Operadora no transporte de cabotagem em complemento ao modal rodoviário:

Figura 1- Fluxo do transporte multimodal, com integração rodoviário, cabotagem rodoviário

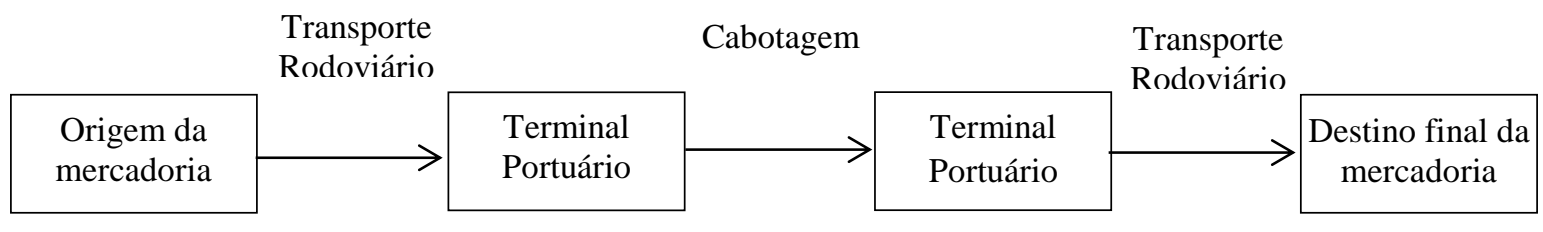

Fonte: Os Autores.

Para o transporte de mercadorias é necessário em ambos os modais a emissão da Nota Fiscal Eletrônica (NF-e) a qual é um recibo transmitido pela internet e obrigatório em qualquer compra e venda de produtos ou serviços, serve para documentar a transação e recolher os devidos impostos. O Documento Auxiliar da NF-e (DANFE) é uma cópia impressa da Nota Fiscal 
que serve para facilitar o acesso aos dados na internet e colher a assinatura do destinatário quando a mercadoria é entregue ao destinatário final (BRASIL, FRETES, 2016).

Além da NF-e, e do DANFE, os documentos básicos obrigatórios para o transporte de cargas normais no modal rodoviário são: o Conhecimento de Transporte Eletrônico (CT-e); Documento Auxiliar do Conhecimento de Transporte Eletrônico (DACTE); o Manifesto Eletrônico de Documentos Fiscais (MDF-e); e Documento Auxiliar do Manifesto Eletrônico de Documentos Fiscais (DAMDFE) (BRASIL FRETES, 2016).

O CT-e é um documento eletrônico da prestação de serviço de transporte de cargas para finalidades fiscais. A garantia da sua validade jurídica depende da assinatura digital do emitente e da recepção e autorização de uso, pelo Fisco. A DACTE é uma cópia impressa da CT-e e deve acompanhar a mercadoria em trânsito. A MDF-e também identifica as características do transporte e o DAMDFE destina-se a acompanhar a mercadoria em trânsito, e visa agilizar o registro dos documentos fiscais em trânsito por lote (BRASIL FRETES, 2016).

Considerando que a Operadora, em transportes através da multimodalidade, e a cabotagem em complemento ao modal rodoviário caso a Operadora possuir habilitação como OTM, a mesma realiza a emissão de Conhecimento de Transporte Multimodal de Cargas (CTMC). O CTMC é um documento fiscal que destaca o contrato de transporte multimodal em toda operação desde o recebimento da mercadoria até a entrega em seu destino final (ANTT, 2017).

Conforme a Operadora consultada, no percurso de cabotagem, pode ocorrer transbordos nos casos de rotas que não tiverem escala direta para o destino final, ou por uma situação operacional, ocorram problemas técnicos no navio ou em determinado porto.

$\mathrm{Na}$ tabela 7 apresenta-se o tempo demandado para o transporte entre Santa Catarina e as cidades de destino da maçã. As cidades de Macapá (AP) e Belém (PA) foram excluídas das avaliações comparativas, pois, as mesmas não possuem rotas de cabotagem (OPERADORA).

Tabela 7 - Tempo de transporte entre Santa Catarina e cidades de destino (em dias)

\begin{tabular}{l|r|c|c|c}
\hline \multicolumn{1}{c|}{ Cidade } & Rodoviário & $\begin{array}{c}\text { Rodoviário - } \\
\text { Cabotagem - } \\
\text { Rodoviário }\end{array}$ & Diferença & $\begin{array}{c}\% \\
\text { Diferença }\end{array}$ \\
\hline Manaus (AM) & 10 & 13 & 3 & 23 \\
Salvador (BA) & 4 & 14 & 10 & 71 \\
Fortaleza (CE) & 6 & 12 & 6 & 50 \\
João Pessoa (PB) & 5 & 12 & 7 & 58 \\
Recife (PE) & 5 & 12 & 7 & 58 \\
Teresina (PI) & 5 & 15 & 10 & 67 \\
Natal (RN) & 6 & 14 & 8 & 57 \\
Aracaju (SE) & 5 & 14 & 9 & 64 \\
\hline
\end{tabular}

Fonte: Operadora e Transportadora.

*No transporte em modal rodoviário na rota de Manaus (AM) inclui-se o trajeto com balsa.

Quanto ao tempo dispendido para o transporte da maçã, o modal rodoviário leva vantagem em todas as rotas, com destaque para Salvador (BA), para cujo destino o modal 
rodoviário demanda aproximadamente $29 \%$ do tempo demandado com a complementação com o modal da cabotagem.

Quando se considera o tempo de transporte demandado, a alternativa da complementação com o modal de cabotagem mostra-se inviável, sobretudo para entregas em curtos prazos. Além disso, as condições operacionais de embarque e desembarque nos portos, para produtos perecíveis, ainda não consolidadas pela experiência, ainda não despertam o interesse por esta multimodalidade de transporte.

\subsection{ANÁLISE DOS CUSTOS}

Com base em dados fornecidos pela Produtora, foi considerada a expedição em contêiner refrigerado de 40' (pés), 1.176 caixas unitizadas com 18 kg liquido de maçãs, representando a carga total aproximada $21.168 \mathrm{~kg}$ por container. O valor estimado da mercadoria transportada, é de $\mathrm{R} \$ 111.720,00$. A maçã é transportada exclusivamente pelo modal rodoviário, por caminhão com baú refrigerado, cuja carga representa o mesmo volume de um container.

Para a comercialização da maçã, as empresas produtoras praticam o preço FOB expedição na maioria dos casos, ficando os custos de frete e os riscos são assumidos pelos clientes. Há exceções quando se trata de vendas diretas a grandes redes de supermercados, quando se praticam os preços CIF, ou seja, as empresas produtoras assumem os custos de frete, seguros, pedágio e demais encargos de transporte até os pontos de entrega das frutas. A tabela 8 apresenta a comparação dos custos de transportes, por carga de maçã transportada.

Tabela 8-Custos de Fretes, Seguros e Pedágio: unitários por carga (R\$)

\begin{tabular}{|c|c|c|c|c|c|c|}
\hline \multirow[b]{2}{*}{ Cidade } & \multicolumn{3}{|c|}{ Rodoviário } & \multicolumn{3}{|c|}{ Rodoviário - Cabotagem - Rodoviário } \\
\hline & $\begin{array}{c}\text { Frete + } \\
\text { Seguros }\end{array}$ & Pedágio & Total & $\begin{array}{c}\text { Frete + } \\
\text { Seguros }\end{array}$ & $\begin{array}{c}\text { Ad. } \\
\text { Valorem }\end{array}$ & Total \\
\hline Manaus (AM) & 34.200 & 440 & 34.640 & 12.570 & 312 & 12.882 \\
\hline Salvador (BA) & 14.800 & 515 & 15.315 & 10.835 & 312 & 11.147 \\
\hline Fortaleza (CE) & 19.400 & 858 & 20.258 & 9.730 & 312 & 10.042 \\
\hline João Pessoa (PB) & 17.800 & 484 & 18.284 & 11.568 & 312 & 11.880 \\
\hline Recife (PE) & 17.000 & 484 & 17.484 & 10.603 & 312 & 10.915 \\
\hline Teresina (PI) & 16.900 & 858 & 17.758 & 13.040 & 312 & 13.352 \\
\hline Natal (RN) & 18.600 & 484 & 19.084 & 12.565 & 312 & 12.877 \\
\hline Aracaju (SE) & 15.200 & 484 & 15.684 & 12.768 & 312 & 13.080 \\
\hline
\end{tabular}

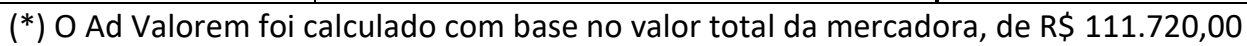

Fonte: Produtora

Os preços de fretes do transporte rodoviário foram obtidos pela Transportadora. Na rota de Manaus, além do frete e do seguro, foi incluído o valor da balsa. No transporte de cabotagem em complemento ao transporte rodoviário, informados pela Operadora, o valor de frete também inclui seguro e a taxa ad valorem de $0,28 \%$ com base no valor da mercadoria. 
Tabela 9 - Custos de frete total e em toneladas ( $R \$$ )

\begin{tabular}{l|rl|rr|rrr}
\hline \multirow{2}{*}{ Cidade } & \multicolumn{2}{c|}{ Rodoviário } & \multicolumn{2}{c|}{ Cabotagem } & \multicolumn{3}{c}{ Diferenças } \\
\cline { 2 - 8 } & \multicolumn{1}{|c|}{ ton. } & \multicolumn{1}{c|}{ Totais } & \multicolumn{1}{c|}{ ton. } & Totais & \multicolumn{1}{c}{ ton. } & \multicolumn{2}{c}{ Totais } \\
\hline Manaus (AM) & 1.633 & 4.714 .471 & 608 & 1.755 .296 & 1.025 & 2.959 .175 & 63 \\
Salvador (BA) & 722 & 4.920 .430 & 526 & 3.584 .690 & 196 & 1.335 .740 & 27 \\
Fortaleza (CE) & 955 & 3.632 .820 & 474 & 1.803 .096 & 481 & 1.829 .724 & 50 \\
João Pessoa (PB) & 862 & 2.027 .424 & 560 & 1.317 .120 & 302 & 710.304 & 35 \\
Recife (PE) & 825 & 4.308 .975 & 515 & 2.689 .845 & 310 & 1.619 .130 & 38 \\
Teresina (PI) & 838 & 3.113 .170 & 630 & 2.340 .450 & 208 & 772.720 & 25 \\
Natal (RN) & 900 & 3.144 .600 & 607 & 2.120 .858 & 293 & 1.023 .742 & 33 \\
Aracaju (SE) & 740 & 1.972 .100 & 617 & 1.644 .305 & 123 & 327.795 & 17 \\
\hline Custos por tonelada & $\mathbf{8 9 9}$ & $\mathbf{2 7 . 8 3 3 . 9 9 0}$ & $\mathbf{5 5 7}$ & $\mathbf{1 7 . 2 5 5 . 6 6 0}$ & $\mathbf{3 4 2}$ & $\mathbf{1 0 . 5 7 8 . 3 3 0}$ & $\mathbf{3 8}$ \\
\hline
\end{tabular}

Fonte: Os Autores

Os maiores ganhos possíveis com a redução de custos de fretes foram apurados para as cidades de Manaus, com ganhos de 63\%, e Fortaleza, com ganhos de 50\%.

Em comparação ao modal exclusivamente rodoviário, a utilização da cabotagem integrada ao modal rodoviário apresenta viabilidade econômica, pois proporciona custos menores para o transporte de longas distâncias, neste estudo, entre a sede da Produtora em Santa Catarina e cidades do Norte e Nordeste do país. A comparação dos custos de transporte indica a possibilidade de uma redução de custos de transporte em favor do transporte multimodal, em aproximadamente 38\%, considerando os volumes transportados no período de 2013 a 2016 .

\section{CONSIDERAÇÕES FINAIS}

Analisou-se neste estudo a viabilidade logística e econômica utilização da cabotagem em complemento ao transporte rodoviário de maçã da região Sul às regiões Nordeste e Norte do Brasil para a Produtora. Para este propósito, apuraram-se os volumes de maçã enviados as regiões Norte e Nordeste do País, nos anos de 2013 a 2016. Apurou-se também o custo do frete no modal exclusivamente rodoviário e no modal rodoviário - cabotagem - rodoviário.

Como contribuição deste estudo, resultados apurados indicam a viabilidade econômica da alternativa do transporte multimodal da maçã, ou seja, a utilização da combinação dos modais rodoviário - cabotagem - rodoviário. Esta alternativa possibilita a redução de custos, em aproximadamente $38 \%$. Adicionalmente, a multimodalidade possui as vantagens na redução das externalidades negativas relacionadas aos transportes (IANNONE, 2012), como poluição, congestionamentos de rodovias, e exposição aos acidentes rodoviários. No entanto, pelas condições de logística, a alternativa multimodal mostra-se inviável, pois requer tempo maior para completar o mesmo percurso. Outra desvantagem da multimodalidade no transporte da maçã, é baixa flexibilidade do sistema logístico, especialmente nas operações de transbordo.

A limitação deste estudo está na consistência de dados secundários, os quais podem apresentar algumas imprecisões decorrentes de amostras insuficientes. Além disso, não se identificou registros de órgãos oficiais sobre volumes de operações interestaduais para a maçã. Outra limitação deste estudo está relacionada ao acesso limitado e à escassez de informações 
sobre a cabotagem principalmente sobre a documentação utilizada e o processo logístico utilizado por este modal.

Sugere-se avaliações futuras, com volumes e escalas maiores, visto que a cabotagem apresenta benefícios adicionais, como a redução da emissão de $\mathrm{CO}^{2}$ na atmosfera, baixo índice de avarias e roubo de cargas, valores de seguro menores e eficiência energética. Também se sugere novos estudos que busquem o aprofundamento referente ao uso do modal da cabotagem, como alternativa para o transporte inter-regional de produtos, envolvendo a multimodalidade e intermodalidade com este modal, inclusive os procedimentos logísticos e os documentos utilizados no modal.

\section{REFERÊNCIAS}

AGÊNCIA NACIONAL DE TRANSPORTES AQUAVIÁRIOS - ANTAQ. Anuário 2015. Brasília, DF, 2016. Disponível em: http://www.antaq.gov.br/Portal/PDF/Anuarios/ApresentacaoAnuario2015.pdf. Acesso em: 25 set. 2016.

AGÊNCIA NACIONAL DE TRANSPORTES TERRESTRES - ANTT. Perguntas frequentes multimodal. Brasília, DF, 2017. Disponível em:

http://www.antt.gov.br/cargas/arquivos_old/Perguntas_Frequentes_Multimodal.html. Acesso em: 30 maio 2017.

BOENTE, Alfredo Nazareno Pereira; RIBEIRO, Luís Otavio de Marind; DORIA, Francisco Antônio de Moraes Accioli; COSENZA, Carlos Alberto Nunes. A importância da intermodalidade / multimodalidade no transporte de cargas no Brasil: uso da lógica fuzzy como ferramenta de aferição. In. XII Congresso Nacional de Excelência em Gestão \& III Inovarse - Responsabilidade Social Aplicada. Rio de Janeiro, 2016. Anais... Rio de Janeiro: 2016. p. 1-14, ref. T16_370. Disponível em: http://www.inovarse.org/sites/default/files/T16_370.pdf. Acesso em: 31 jan. 2019.

BRASIL. Lei no 9.611, de 19 de fevereiro de 1998. Dispõe sobre o Transporte Multimodal de Cargas e dá outras providências. Diário Oficial da União, Seção 1, Brasília, DF, p. 9, 20 fev.1998. PL 4586/1990. Disponível em: https://www2.camara.leg.br/legin/fed/lei/1998/lei-9611-19fevereiro-1998-365400-publicacaooriginal-1-pl.html. Acesso em: 30 maio 2017.

BRASIL FRETES. Documentação básica necessária para o transporte rodoviário de cargas. São Paulo, 23 nov. 2016. Disponível em: https://www.brasilfretes.com.br/documentacao-basicanecessaria-para-o-transporte-rodoviario-de-cargas/. Acesso em: 19 maio 2017.

CASTRO, Danilo Medeiros; REIS, João Gilberto Mendes dos; VENDRAMETTO, Oduvaldo; LOPES, Antônio Carlos Vaz. Modelo de decisão multicritério para escolha do modo de transporte: um estudo do escoamento da produção de grãos de Mato Grosso do Sul. Revista Produção Online, Florianópolis, v. 16, n. 4, p. 1214-1236, 2016. ISSN 16761901. 
CONFEDERAÇÃO NACIONAL DO TRANSPORTE - CNT. Boletim Estatístico Julho de 2016. Brasília: CNT. 2016. Disponível em: http://www.cnt.org.br/Boletim/boletim-estatistico-cnt. Acesso em: 25 set. 2016.

. Pesquisa CNT do transporte aquaviário: Cabotagem 2013. Brasília: CNT, 2013. Disponível em: http://www.cnt.org.br/Pesquisa/pesquisa-transporte-aquaviario-cabotagem2013. Acesso em 16 out. 2016.

. Pesquisa CNT do transporte marítimo 2012. Brasília: CNT. 2012. 267 p. Disponível em: https://www.academia.edu/7411179/Pesquisa_do_Transporte_Maritimo_CNT_2012. Acesso em 16 out. 2016.

CRUZ, Simone Maria Lucena; ARAÚJO, Maria Creuza Borges de; ALENCAR, Luciana Hazin. Transporte de cabotagem no Porto de Suape, Pernambuco: uma pesquisa exploratória. Production, v. 25, n. 3, p. 560-570, 2015.

EMPRESA DE PESQUISA AGROPECUÁRIA E EXTENSÃO RURAL DE SANTA CATARINA - CENTRO DE SOCIOECONOMIA E PLANEJAMENTO AGRÍCOLA - EPAGRI/CEPA. Síntese Anual da Agricultura. 2014-2015. Florianópolis: Epagri/Cepa.156 p. 2015. Disponível em:

http://docweb.epagri.sc.gov.br/website_cepa/publicacoes/Sintese_2015.pdf. Acesso em: 26 out. 2016. ISSN: 1677-5953.

FACHINELLO, Arlei Luiz; NASCIMENTO, Sidnei Pereira. Cabotagem como alternativa para o transporte de carnes da região Sul para o Norte/Nordeste brasileiro: um estudo de caso. Revista de Economia e Sociologia Rural - RESR, Piracicaba, v. 46, n. 04, p. 969-988, out/dez, 2008.

FACHIN, Odília. Fundamentos de metodologia. 5. ed. São Paulo: Editora Saraiva. 2006. 206 p. ISBN: 9788502055322.

GIL, Antonio Carlos. Como elaborar projetos de pesquisas. 5. ed. São Paulo: Editora Atlas. 2010. 184 p. ISBN: 9788522458233.

GUIA MARÍTIMO. Especial Multimodalidade. São Paulo: $2016 a .60$ p. Disponível em: http://www.guiamaritimo.com.br/files/originals/ESPECIALAGOSTOMultimodal.pdf. Acesso em: 14 out. 2016.

IANNONE, Fedele. The private and social cost efficiency of port hinterland container distribution through a regional logistics system. Transportation Research Part A: Policy and Practice, v. 26, n. 9, p. 1424-1448, 2012. http://dx.doi.org/10.1016/j.tra.2012.05.019.

INSTITUTO BRASILEIRO DE GEOGRAFIA E ESTATÍ́STICA - IBGE. Sistema IBGE de Recuperação Automática - SIDRA. Produção Agrícola Municipal. Rio de Janeiro: 2016. Disponível em: https://sidra.ibge.gov.br/tabela/1613. Acesso em: 26 out. 2016. 
INSTITUTO DE LOGISTICA E SUPPLY CHAIN - ILOS. Custos logísticos no Brasil. Rio de Janeiro: 2016a. Disponível em: http://www.ilos.com.br/web/analise-de-mercado/relatorios-depesquisa/custos-logisticos-no-brasil/. Acesso em: 31 ago. 2016.

Cabotagem e redução de custos na logística. Rio de Janeiro, 2016b. Disponível em: http://www.ilos.com.br/web/artigos/. Acesso em: 31 ago. 2016.

JACOBSEN, Mércio. Administração de materiais. Um enfoque logístico. Itajaí: Univali: ed. 2011. 271 p. ISBN: 88576960829.

KEEDI, Samir. Transportes, unitização e seguros internacionais de carga. 2. ed. São Paulo: Aduaneiras, 2003. 216 p. ISBN: 9788571295582

KEEDI, Samir; MENDONÇA, Paulo de. Transportes e seguros no comércio exterior. São Paulo. Aduaneiras, 2000. 254 p. ISBN: 8571292280

KIST, Benno Bernardo; JUNGBLUT, Guido; ASSMANN, Inor; ÁVILA, Sílvio; MACHADO, Márcio Oliveira; VEIGA, Sadraque Lenz; LENZ, Andréa; KNAK, Ana Paula; BUGS, Maira Trojan; LANGBECKER, Janaína; KAEMPF, Gabriela; MORAES, Simone. Anuário brasileiro da maçã 2016. Santa Cruz do Sul: Editora Gazeta Santa Cruz. 2016. 64 p. Disponível em: http://www.abpm.org.br/wp-content/uploads/2018/02/anuario_maca_2016.pdf. Acesso em: 09 set. 2016. ISSN 2446-8657.

LOGÍSTICA INTERMODAL S/A. - LOG-IN. Entendendo a cabotagem. [S.I.]. 2016a. Disponível em: https://www.loginlogistica.com.br/entendendo-a-cabotagem. Acesso em: 25 set. 2016.

Cabotagem. [S.I.]. 2016b. Disponível em:

https://www.loginlogistica.com.br/cabotagem. Acesso em: 25 set. 2016.

. Transporte porta a porta. [S.I.]. 2017. Disponível em:

https://www.loginlogistica.com.br/transporte-porta-a-porta. Acesso em: 30 mai. 2017.

MARCONI, Marina de Andrade; LAKATOS, Eva Maria. Fundamentos de metodologia cientifica. 7. ed. São Paulo: Editora Atlas. 2010. 297 p. ISBN: 9788522457588.

MEDEIROS Paulo Vinícius Menezes de. Políticas de infraestrutura de transportes no Brasil: investimentos, multimodalidade e configuração regional no plano nacional de logística e transporte (PNLT). 2014. 175 f. Dissertação (Mestrado em Economia) - Universidade Federal de Uberlândia, Uberlândia: 2014. Disponível em:

https://repositorio.ufu.br/bitstream/123456789/13587/1/PoliticasInfraestruturaTransportes_p arte\%201.pdf. Acesso em 01 fev.2019. 
MENDONÇA, José Carlos de. Containers: manuseio de cargas perecíveis. Prates e Mendonça Consultoria. São Paulo. [2016]. Disponível em:

http://www.pratesmendonca.com.br/containeres-manuseio-de-cargas-pereciveis.html. Acesso em: 26 out. 2016.

MINISTÉRIO DA AGRICULTURA PECUÁRIA E ABASTECIMENTO - MAPA - Secretaria de Política Agrícola de Maçã. Informativo no 54. Ano 6 Vol. 54, Brasília, DF, março de 2013. Disponível em: http://www.agricultura.gov.br/assuntos/politica-agricola/arquivos-de-estatisticas/informativo__maca_2013_-2-1.pdf. Acesso em: 10 set. 2016.

NOVAES, Antonio Galvão. Logística e gerenciamento da cadeia de distribuição: estratégia operação e avaliação. 4. ed. Rio de Janeiro: Elsevier Editora, 2015. 402 p. ISBN 8535224157

REIS, Velasco; MEIER, J. Fabian; PACE, Giuseppe; PALACIN, Roberto. Rail and multi-modal transport. Research in Transportation Economics, v.41, n.1, p.17-30, 2013.

http://doi.org/10.1016/j.retrec.2012.10.005.

RIBEIRO, Luís Otávio de Marins; BOENTE, Alfredo Nazareno Pereira. A Intermodalidade e o Transporte de Carga no Brasil: Uma Visão de Aplicabilidade na Lógica Fuzzy. In: XVII SIMPÓSIO DE ADMINISTRAÇÃO DA PRODUÇÃO, LOGÍSTICA E OPERAÇÕES INTERNACIONAIS. São Paulo. Anais... São Paulo: SIMPOI. 2014, vol. 1, p. 1-14. Disponível em: https://docplayer.com.br/11220549-Anais-a-intermodalidade-e-o-transporte-de-carga-nobrasil-uma-visao-de-aplicabilidade-na-logica-fuzzy.html. Acesso em: 19 maio 2017.

RODRIGUES, Paulo Roberto Ambrósio. Introdução aos sistemas de transporte no Brasil e à logística internacional. 4. ed. São Paulo: Aduaneiras, 2007. 248 p. ISBN: 9788571294905.

RODRIGUES, Paulo Roberto Ambrósio; FIGUEIREDO, Isabel Bernardo Dias de; MENEZES, Júlio Eduardo da Silva; LUDOVICO, Nelson. Gestão de Logística Internacional. Rio de Janeiro: FGV Editora. 2014. 158 p. ISBN: 9788522514236.

SILVA, Diogo Palheta Nery; SPROESSER, Renato Luiz; SPERS, Renata Giovinazzo. Sustentabilidade socioambiental dos terminais intermodais do Brasil: um estudo exploratório. Revista Metropolitana de Sustentabilidade, São Paulo: v. 7, n. 2, p. 20-42, 2017. Disponível em: http://www.revistaseletronicas.fmu.br/. Acesso em 01 fev. 2019. ISSN 2318-3233.

SILVA, Luciana Amorim Carlos; ARAÚJO, Maria Valeria Pereira; BRITO, Max Leandro de Araújo. Logística intermodal no estado do Rio Grande do Norte: um estudo exploratório. Research, Society and Development, Itabira, v. 7, n. 7, p. 01-21, 2018.

SILVA, Luiz Augusto Tagliacollo. Logística no comercio exterior. 4. ed. São Paulo: Aduaneiras, 2004. 150 p. ISBN: 9788571294417. 
SILVEIRA, Marcio Rogério; FELIPE JUNIOR, Nelson Fernandes. A Dinâmica do Transporte Marítimo de Cabotagem e Longo Curso no Brasil: Circulação do Capital e Modernizações. Geosul, Florianópolis: v. 28, p. 07-29, 2013.

SOCIEDADE NACIONAL DE AGRICULTURA - SNA. Resfriamento na conservação das frutas e hortaliças. Rio de Janeiro: 2014. Disponível em: http://sna.agr.br/resfriamento-na-conservacaodas-frutas-e-hortalicas/. Acesso em 11 set. 2016

SOUZA, Rodrigo Oliveira; CREMASCO, Camila Pires; GABRIEL FILHO, Luís Roberto Almeida. Análise dos valores de frete da soja a granel nos sistemas unimodal e multimodal de transporte. RAMA - Revista em Agronegócio e Meio Ambiente, Maringá: v. 9, p. 819-837, 2016.

http://dx.doi.org/10.17765/2176-9168.20169n4p803-818 